\title{
Article \\ COVID-19 in Patients with Inflammatory Bowel Disease: The Israeli Experience
}

\author{
Lev Lichtenstein ${ }^{1}$, Benjamin Koslowsky ${ }^{2}$, Ami Ben Ya'acov ${ }^{2}{ }^{(}$, Irit Avni-Biron ${ }^{3,4}$, Baruch Ovadia ${ }^{5}$, \\ Ofer Ben-Bassat ${ }^{6}$, Timna Naftali ${ }^{4,7}$, Uri Kopylov ${ }^{4,8}$, Yael Haberman ${ }^{4,8} \mathbb{D}$, Hagar Banai Eran ${ }^{3,4}$, Rami Eliakim ${ }^{4,8}$, \\ Adi Lahat-Zok ${ }^{4,8}$, Ayal Hirsch 4,9 ${ }^{\mathbb{D}}$, Eran Zittan 10,11, Nitsan Maharshak 4,9 ${ }^{\mathbb{D}}$, Matti Waterman 11,12 (D), \\ Eran Israeli ${ }^{4,13}$, Idan Goren ${ }^{3,4}{ }^{\mathbb{D}}$, Jacob E. Ollech ${ }^{3,4}$, Henit Yanai ${ }^{3,4}$, Bella Ungar 4,8, Benjamin Avidan ${ }^{4,8}$, \\ Dana Ben Hur 11,12, Bernardo Melamud 4,13, Ori Segol 14, Zippora Shalem 4,15, Iris Dotan 3,4, Selwyn H. Odes 4,16, \\ Shomron Ben-Horin ${ }^{4,8}$, Yf' at Snir ${ }^{3,4}$, Yael Milgrom ${ }^{17}$ (D), Efrat Broide ${ }^{4,15}$, Eran Goldin ${ }^{2}$, Shmuel Delgado ${ }^{18}$, \\ Yulia Ron ${ }^{4,9}$, Nathaniel Aviv Cohen ${ }^{4,9}$, Eran Maoz ${ }^{1}$, Maya Zborovsky ${ }^{1}$, Safwat Odeh ${ }^{19}$, Naim Abu Freha ${ }^{20}$, \\ Eyal Shachar ${ }^{4,8}$, Yehuda Chowers ${ }^{11,12}$, Tal Engel 4,8, Hila Reiss-Mintz ${ }^{4,16}$, Arie Segal ${ }^{20}$, Adar Zinger 17 \\ and Ariella Bar-Gil Shitrit ${ }^{2, *}$
}

check for updates

Citation: Lichtenstein, L.; Koslowsky, B.; Ben Ya'acov, A.; Avni-Biron, I.; Ovadia, B.; Ben-Bassat, O.; Naftali, T.; Kopylov, U.; Haberman, Y.; Eran, H.B.; et al. COVID-19 in Patients with Inflammatory Bowel Disease: The Israeli Experience. Vaccines 2022, 10, 376. https://doi.org/10.3390/ vaccines10030376

Academic Editor: Peter Maple

Received: 27 January 2022

Accepted: 24 February 2022

Published: 28 February 2022

Publisher's Note: MDPI stays neutral with regard to jurisdictional claims in published maps and institutional affiliations.

Copyright: (C) 2022 by the authors. Licensee MDPI, Basel, Switzerland. This article is an open access article distributed under the terms and conditions of the Creative Commons Attribution (CC BY) license (https:// creativecommons.org/licenses/by/ $4.0 /)$.
Clalit Health Services, Tel Aviv, Israel

2 Digestive Diseases Institute, Shaare Zedek Medical Center, Faculty of Medicine, Hebrew University of Jerusalem, Jerusalem, Israel

Division of Gastroenterology, Rabin Medical Center, Petah Tikva, Israel

Sackler Faculty of Medicine, Tel Aviv University, Tel Aviv, Israel

Department of Gastroenterology and Hepatology, Hillel Yaffe Medical Center, Hadera, Israel

6 Barzilai Medical Center, Ashkelon, Israel

Department of Gastroenterology and Liver Diseases, Meir Medical Center, Kfar Saba, Israel

8 Department of Gastroenterology, Chaim Sheba Medical Center, Tel Hashomer, Ramat Gan, Israel

9 Sourasky Medical Center, Tel Aviv, Israel

10 Inflammatory Bowel Disease Unit, Ha'emek Medical Center, Faculty of Medicine, Israel Institute of Technology, Afula, Israel

11 Faculty of Medicine, Israel Institute of Technology, Haifa, Israel

12 Rambam Medical Center, Faculty of Medicine, Tel Aviv University, Tel Aviv, Israel

3 Department of Gastroenterology and Liver Diseases, Wolfson Medical Center, Holon, Israel

14 Unit of Gastroenterology, Lady Davis Carmel Medical Center, Haifa, Israel

15 Gastroenterology and Liver Diseases Institute, Shamir Medical Center, Be'er Ya'akov, Israel

16 Mayanei HaYeshua Medical Center, Bnei Brak, Israel

17 Hadassah Medical Center, Jerusalem, Israel

18 Assuta Medical Center, Ben-Gurion University, Negev, Be'er Sheva, Israel

19 Bnai Zion Medical Center, Haifa, Israel

20 Soroka Medical Center, Be'er Sheva, Israel

* Correspondence: ariellash@szmc.org.il

\begin{abstract}
Background: Crohn's disease (CD) and ulcerative colitis (UC) are chronic, immunemediated inflammatory bowel diseases (IBD) affecting millions of people worldwide. IBD therapies, designed for continuous immune suppression, often render patients more susceptible to infections. The effect of the immune suppression on the risk of coronavirus disease-19 (COVID-19) is not fully determined yet. Objective: To describe COVID-19 characteristics and outcomes and to evaluate the association between IBD phenotypes, infection outcomes and immunomodulatory therapies. Methods: In this multi-center study, we prospectively followed IBD patients with proven COVID-19. De-identified data from medical charts were collected including age, gender, IBD type, IBD clinical activity, IBD treatments, comorbidities, symptoms and outcomes of COVID-19. A multivariable regression model was used to examine the effect of immunosuppressant drugs on the risk of infection by COVID-19 and the outcomes. Results: Of 144 IBD patients, 104 (72\%) were CD and 40 $(28 \%)$ were UC. Mean age was $32.2 \pm 12.6$ years. No mortalities were reported. In total, 94 patients $(65.3 \%)$ received biologic therapy. Of them, 51 (54\%) at escalated doses, 10 (11\%) in combination with immunomodulators and $9(10 \%)$ with concomitant corticosteroids. Disease location, behavior and activity did not correlate with the severity of COVID-19. Biologics as monotherapy or with im-
\end{abstract} munomodulators or corticosteroids were not associated with more severe infection. On the contrary, 
patients receiving biologics had significantly milder infection course $(p=0.001)$ and were less likely to be hospitalized ( $p=0.001$ ). Treatment was postponed in $34.7 \%$ of patients until recovery from COVID-19, without consequent exacerbation. Conclusion: We did not witness aggravated COVID-19 outcomes in patients with IBD. Patients treated with biologics had a favorable outcome.

Keywords: COVID-19; Crohn's disease; ulcerative colitis; inflammatory bowel disease; biological drugs; immune suppression

\section{Introduction}

Inflammatory bowel disease (IBD) is a complex, multifactorial chronic inflammatory disease of the gastrointestinal tract encompassing two main clinical entities: Crohn's disease (CD) and ulcerative colitis (UC). Given the immunological signature of IBD, the current treatment strategies frequently involve immunosuppressive drugs that are aimed at controlling the excessive intestinal immune response. The extensive use of these therapies among patients with IBD increases their risk of opportunistic and severe infections [1,2]. Patients with IBD are among millions of people that have been affected by the novel severe acute respiratory syndrome coronavirus 2 (SARS-CoV-2). Coronavirus disease-19 (COVID-19) is an infectious disease caused by SARS-CoV-2 [3] that is rapidly evolving affecting individuals of all ages, thus creating an ongoing global health crisis. SARS-CoV2 enters host cells via angiotensin-converting enzyme 2 (ACE2) which is constitutively expressed by epithelial cells in various organs. Its expression in the terminal ileum and colon are amongst the highest in the body [4]. Although most cases of COVID-19 are mild, the disease can become severe and result in hospitalization, acute respiratory distress syndrome (ARDS) or multi-organ failure and death [3,5]. Data from recent waves of COVID19 infections suggest that patients with underlying comorbidities are at greater risk to be infected by SARS-CoV-2 [6,7]. Immunosuppressed patients with IBD are included in this group. Nevertheless, in a recent large cohort of 5302 IBD patients only $39(0.7 \%)$ developed COVID-19 [8]. In another population-based study, patients with IBD were more likely to be hospitalized due to COVID-19; however, the risk of severe COVID-19 was not higher than the general population [9]. A panel of the international organization for the study of inflammatory bowel diseases (IOIBD) has recently stated that having IBD did not increase the risk of developing COVID-19 $[10,11]$. However, data on the clinical course of COVID19 among IBD patients especially in regard to immunosuppressive treatments remains relatively scarce. In the current work we prospectively collected data from COVID-19 patients with IBD and analyzed their outcomes with regard to their IBD treatment.

\section{Materials and Methods}

\subsection{Study Setting}

This nation-wide collaborative registry was initiated by the Israeli IBD Society at the start of the COVID-19 pandemic in March 2020, in order to monitor outcomes of COVID-19 among adult and pediatric patients with IBD. Seventeen IBD referral units in academic and non-academic hospitals and health centers affiliated with the Israeli IBD Society participated in the study. Physicians were prompted to report cases of PCR-confirmed COVID-19 occurring in patients with IBD, regardless of IBD treatment or infection severity. Patients were enrolled from March through October 2020.

\subsection{Participants}

Patients with established CD or UC were enrolled in 17 participating IBD centers. For all eligible patients, de-identified data from medical charts were collected, including age, gender, IBD type, IBD clinical activity, IBD treatments and comorbidities. UC and CD were defined according to the Montreal classification [12]. In UC patients, disease extension was classified to E1 (proctitis), E2 (left-sided) or E3 (extensive UC). The severity was classified 
as S0 (asymptomatic), S1 (mild), S2 (moderate) and S3 (severe). In CD patients, location was classified as L1 (ileal), L2 (colonic), L3 (ileocolonic) or L4 (isolated upper disease). Age at diagnosis was classified as A1 (below 16 years), A2 (between 17 and 40 years) and A3 (above 40 years). Behavior was classified as B1 (non-stricturing, non-penetrating), B2 (structuring) or B3 (penetrating).

\subsection{Outcomes and Definitions}

The primary objective of this study was to describe COVID-19 characteristics in patients with IBD. COVID-19 was defined as a positive PCR test for SARS-CoV-2 on a nasopharyngeal swab. For COVID-19 symptoms we used the definitions of the NIH for illness categories: asymptomatic infection, moderate, severe and critical illness [13]. In the present study the characteristics are described in terms of severe outcomes, such as hospitalization, need for respiratory support, intensive care and mortality. The secondary objective was to investigate possible associations between severe infection outcomes, IBD phenotypes and immunosuppressive/biologic treatments.

\subsection{Research Ethics and Patient Consent}

The study was approved on February 2020 by the institutional review board (no: 002019) of Shaare Zedek Medical Center (SZMC), as well as by the Ministry of Health Ethics Committee. All participants in the study had approval of their institution as well. The study protocol conforms to the ethical guidelines of the 1975 Declaration of Helsinki as reflected in a priori approval by the institutional human research committee. Participating centers reported de-identified data, in accordance with the HIPAA De-Identification standards.

\subsection{Statistical Analysis}

Categorical variables were compared using Chi-square test or Fisher's exact test. Continuous variables were analyzed by Wilcoxon signed ranks test or paired samples t-test, according to variable distribution. All tests were two-tailed and significance was defined as $p$-value $<0.05$. The data were analyzed using software package for statistics (IBM, SPSS version 25$)$.

\section{Results}

\subsection{IBD Patient Characteristics}

Between March and October 2020, 144 patients with an established IBD diagnosis and confirmed COVID-19 were enrolled at 20 IBD referral units. Patient demographic and clinical characteristics are shown in Table 1 . Most patients were under the age of $40(113,78.4 \%) ; 9$ were under the age of $18(6.3 \%)$ and only 4 were above the age of 70 $(2.8 \%)$. In total, 104 had CD (72.2\%) and $40(27.8 \%)$ had UC. Mean age was $32.2 \pm 12.6$ years. Obesity was reported in $17(11.8 \%)$ patients. Other comorbidities included diabetes (5.6\%), asthma or chronic obstructive pulmonary disease (COPD) (4\%) and congestive heart failure (CHF) (1.4\%). The cohort included 14\% tobacco smokers and $10 \%$ cannabis users (either oil or smokers). IBD characteristics were based on the Montreal classification [12]. For CD patients, 35.6\% were A1, 53.8\% A2 and 7.7\% A3. The location was ileal (L1) in 43.3\%, followed by ileocolonic (L3) $36.5 \%$, and colonic (L2) $17.3 \%$. A total of $8.7 \%$ of patients also presented with isolated upper disease (L4). Neither disease location nor behavior or activity correlated with the severity of COVID-19 infection. Additionally, 16.3\% of CD patients and $30 \%$ of UC patients were infected by SARS-CoV-2 while in remission, the rest were reported with moderate disease. 
Table 1. Patient characteristics.

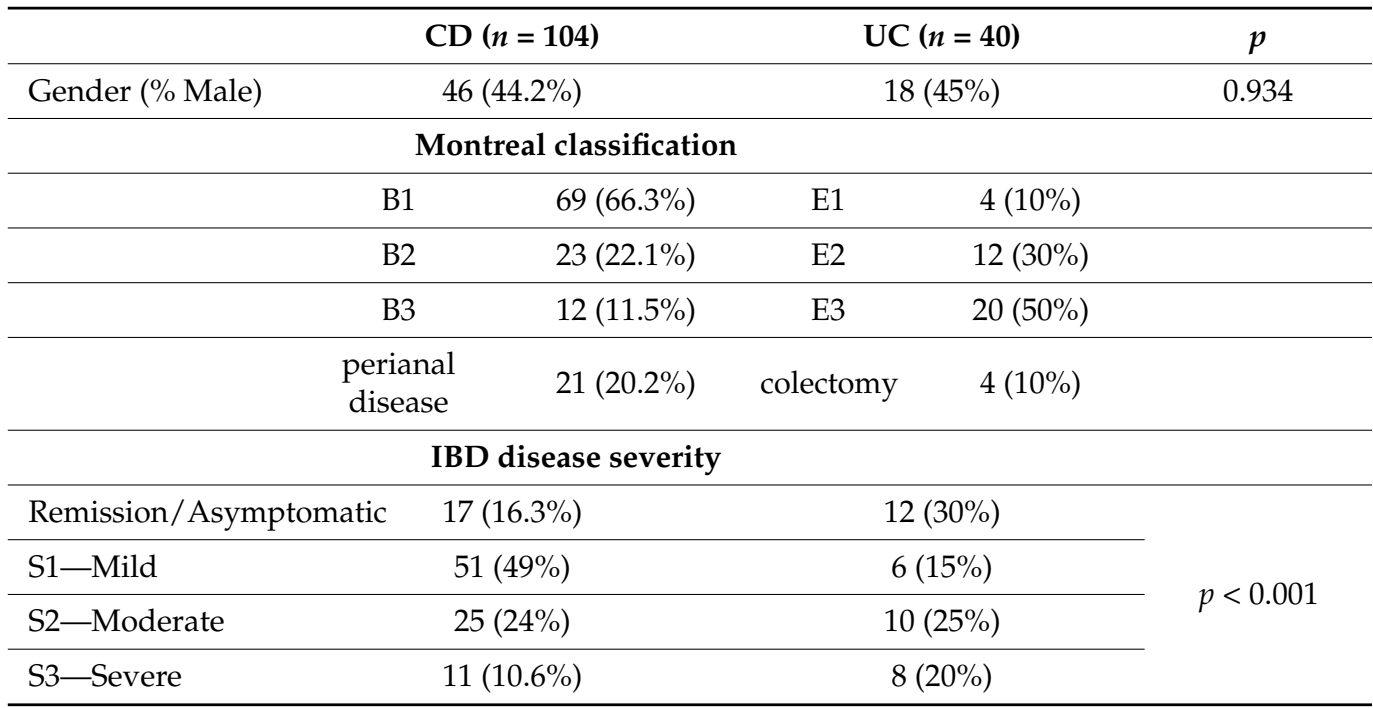

IBD treatments are summarized in Table 2. Eighteen subjects did not receive any treatment. Ninety-four patients (65.3\%) received biologics, either as a monotherapy (52.8\%), or combined with immunomodulators (IM) $(11 \%)$ or with concomitant corticosteroids $(10 \%)$. One patient received biologics combined with IM and corticosteroids. Three patients received Tofacitinib and four patients were on a clinical trial medication (either new biologic or small molecule). Fifty-one (51\%) patients received biologics at escalated doses. In a third of the patient population $(34.7 \%)$ the treatment was postponed until recovery from COVID-19, with no resulting IBD exacerbation.

Table 2. IBD treatments in the patient cohort.

\begin{tabular}{|c|c|c|c|c|}
\hline Treatment & Total $(n)$ & Mild/Asy & ate/Severe & $p$ \\
\hline Anti-TNF & 52 & 50 & 2 & $p=0.002$ \\
\hline Vedolizumab & 23 & 22 & 1 & $p=0.084$ \\
\hline Ustekinumab & 12 & 10 & 2 & 1 \\
\hline Other * & 7 & & & \\
\hline Total biologics & 94 & 87 & 7 & $<0.001$ \\
\hline Biologics only & 76 & 71 & 5 & 0.001 \\
\hline Biologics + steroids & 9 & 7 & 2 & 0.644 \\
\hline Biologics + IM & 10 & 10 & 0 & 0.143 \\
\hline IM monotherapy & 12 & 11 & 1 & 0.418 \\
\hline Steroids only & 8 & 7 & 1 & 0.745 \\
\hline $\begin{array}{l}\text { IM monotherapy + } \\
\text { steroids }\end{array}$ & 2 & 2 & 0 & 0.524 \\
\hline 5-ASA & 29 & 25 & 4 & 0.642 \\
\hline none & 18 & 7 & 11 & $<0.001$ \\
\hline
\end{tabular}

* Other included tofacitinib and trial biologics treatments. IM; immunomodulators, including methotrexate.

\subsection{COVID-19 Characteristics in IBD Patients}

Reported COVID-19 symptoms are summarized in Table 3. CD patients were more prone to severe COVID-19 than UC patients $(p=0.08)$. Most patients presented with mild disease and were treated at a home setting $(p=0.747)$. In addition, there was no correlation between IBD severity (as presented in Table 1) to COVID-19 severity, when divided into 
CD and UC ( $p=0.49$ and $p=0.7$ for CD and UC, respectively). There was no significant difference between CD and UC groups in any symptom, except for shortness of breath that was more frequent in subjects with UC $(p=0.009)$. As for the GI symptoms, there was also no apparent aggravation of diarrhea (defined by before/after reported number of bowel movements). A small percentage suffered from vomiting or nausea. Overall, 24 patients (16.6\%) were admitted for hospitalization, the rest were managed either by HMO (health maintenance organization) teams in home hospitalization set up (114, 76.2\%), or by Home Front Command medical teams in hotels converted into makeshift healthcare facilities. Three hospitalized patients required endotracheal intubation and mechanical ventilation $(2 \%)$, while $15(10.4 \%)$ required non-invasive ventilation and oxygen support. There were no mortalities. All patients recovered from the infection uneventfully. As expected, age over 50 was significantly correlated to severe disease $(p=0.001)$.

Table 3. COVID-19 characteristics according to CD and UC populations.

\begin{tabular}{|c|c|c|c|}
\hline IBD & $\mathrm{CD}(n=104)$ & $\mathrm{UC}(n=40)$ & $p$ Value \\
\hline Asymptomatic & $25(24 \%)$ & $5(12.5 \%)$ & \multirow{4}{*}{0.08} \\
\hline Mild & $64(61.5 \%)$ & $26(65 \%)$ & \\
\hline Moderate & $8(7.7 \%)$ & $8(20 \%)$ & \\
\hline Severe & $7(6.7 \%)$ & $1(2.5 \%)$ & \\
\hline \multicolumn{4}{|l|}{ Setting } \\
\hline Home & $84(80.8 \%)$ & $30(75 \%)$ & \multirow{3}{*}{0.747} \\
\hline Hotel & $4(3.8 \%)$ & $2(5 \%)$ & \\
\hline Hospital & $16(15.4 \%)$ & $8(20 \%)$ & \\
\hline \multicolumn{4}{|c|}{ Symptoms for COVID-19 } \\
\hline Fever & $49(47.1 \%)$ & $16(40 \%)$ & 0.442 \\
\hline Cough & $43(41.3 \%)$ & $15(37.5 \%)$ & 0.673 \\
\hline Shortness of breath & $9(8.7 \%)$ & $10(25 \%)$ & 0.009 \\
\hline Fatigue & $9(8.7 \%)$ & $3(7.5 \%)$ & 0.822 \\
\hline Headache & $9(8.7 \%)$ & $5(12.5 \%)$ & 0.485 \\
\hline Dysgeusia & $13(12.5 \%)$ & $5(12.5 \%)$ & 1 \\
\hline Throat ache & $4(3.8 \%)$ & $3(7.5 \%)$ & 0.361 \\
\hline GI Pain & $19(18.3 \%)$ & $8(20 \%)$ & 0.3 \\
\hline Vomiting & $5(4.8 \%)$ & $2(5 \%)$ & 0.693 \\
\hline Nausea & $2(1.9 \%)$ & $1(2.5 \%)$ & 0.65 \\
\hline Diarrhea * & $11(10.5 \%)$ & $6(15 \%)$ & 0.46 \\
\hline
\end{tabular}

\subsection{Biological Treatments for IBD May Be Associated with Favorable Course of COVID-19}

We tested whether any IBD treatment is correlated to COVID-19 severity. Interestingly, we found that overall patients that received biologics had a significantly milder course of disease ( $p=0.001$, Figure 1A). This finding remained significant following multivariate regression that took into account other treatments, as well as the type of disease, age over 50, gender, smoking status, obesity and comorbidities $(p=0.016, \mathrm{OR}=0.07, \mathrm{CI}$ 95\%: 0.009-0.621). In addition, more patients in the no-biologics group were hospitalized $(p<0.001$, Figure 1B). When testing sub-groups of biologics, we found that among 52 patients treated with anti TNF, only 4 patients $(7.7 \%)$ were hospitalized. Disease severity was significantly $(p=0.021)$, lower in this subgroup of patients treated with anti TNF, with only one severe and one moderate patient. Notably, $61 \%(11 / 18)$ of patients who did not receive any IBD treatment suffered from moderate or severe symptoms. 
A

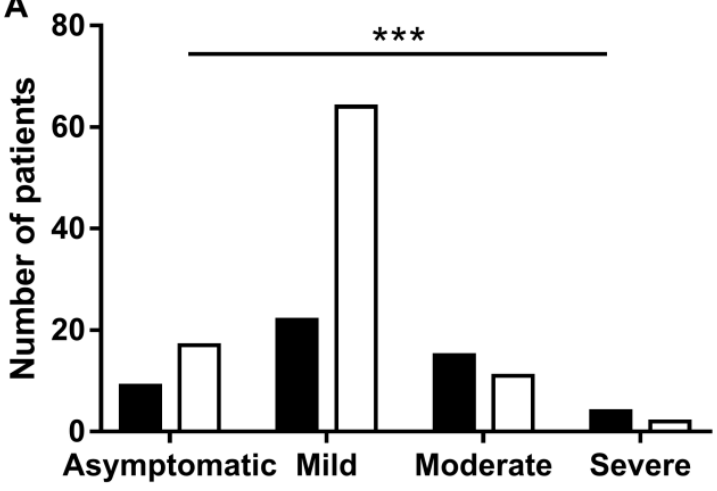



Figure 1. Association between IBD treatment and COVID-19 severity. (A) Number of IBD patients with various degrees of COVID-19 severity comparing biological therapy and non-biological therapy. (B) Outcome of COVID-19 in patients with IBD, comparing biological therapy and non-biological therapy. The $p$-value is based on a Pearson Chi-square test comparing patient distribution between groups (biological therapy and non-biological therapy), with $p<0.001\left({ }^{* *}\right)$ in all degrees of COVID-19 severity and outcomes.

\section{Discussion}

Patients with IBD are primarily treated by immunosuppressive medications. Thus, during the outbreak of COVID-19 there was increasing concern regarding their risk of being infected with SARS-CoV-2. Accumulating data from the last 2 years found no evidence for an increased susceptibility to COVID-19 among patients with IBD [9,10,14-17]. In our prospective observational study, we found that IBD patients treated with biological medications even had a protecting effect from severe SARS-CoV-2 infection. Similarly, one of the first observations of SARS-CoV-2 from Wuhan, China did not report any COVID19 case among 318 IBD patients [18]. Anti-TNF antibodies are frequently used for IBD therapy [19-21]. Our cohort included 52 patients who received anti-TNF treatments and experienced only a mild course of COVID-19. These results are in line with the decreased risk for hospitalization reported in anti TNF-treated patients with other rheumatic diseases who were infected with COVID-19 [22]. The expression of ACE2 is increased in the inflamed gut of patients with IBD [23]. On the other hand, the level of soluble ACE2, a different form of this protein that lacks the membrane anchor and circulates in small amounts in the blood, is also upregulated in the blood of patients with IBD [24]. Therefore, soluble ACE2 might be a competitive interceptor for SARS-CoV-2 by preventing the binding of the viral particle to the surface-bound, full length ACE2 [25]. These observations suggest a limited infection rate for IBD patients. Mehta et al. showed that TNF may also exert pathogenic effects by augmenting the expression of ACE2 or by augmenting lymphopenia through induction of direct leucocyte death via T cell TNF or TNF receptor signaling [26]. Furthermore, Burgueno et al. have recently showed that the expression of ACE2 was not increased in patients with IBD and further therapy with biologics may decrease the expression of these receptors, resulting in overall support for a milder course in IBD patients [27]. Moreover, a new trial recently launched will investigate whether adalimumab, an anti-TNF drug, is effective for treating COVID-19 patients in the community [28]. Our data supports these reports, as we show favorable outcomes in our cohort, which included 31 patients receiving adalimumab. Taken together, the favorable outcome observed in IBD patients treated with anti TNFs support a potentially protective effect of TNF inhibition in COVID-19, but further investigations are required.

Vedolizumab, a selective $\alpha 4 \beta 7$ inhibitor, and Ustekinumab, an IL12/23 inhibitor, are usually given to IBD patients who have failed or who are intolerant of anti-TNF therapy. Both drugs are approved for IBD and no increase in viral infections has been noted in patients treated with these agents. Vedolizumab was given to 23 patients and Ustekinumab was given to 12 patients in our study, none of them experienced severe course of COVID-19. 
Thiopurine (azathioprine, 6-mercaptopurine) and JAK1/3 inhibitor (tofacitinib) treatments can potentially reduce the number of activated $\mathrm{T}$ cells and affect $\mathrm{T}$-cell activation and effector function. Although no data are currently available in this context, it might affect the course of COVID-19, as lymphopenia was associated with worse prognosis in this disease. Moreover, tofacitinib was reported to increase the risk for certain viral infections (e.g., herpes zoster) $[29,30]$. Since our cohort included only seven patients on tofacitinib, it is difficult to draw any specific conclusions. However, we can report that only one patient experienced a severe course of infection. In contrast to biologic drugs, corticosteroids which are also very common in treating IBD were found to be associated with adverse COVID-19 outcomes. The SECURE-IBD is a large international registry that was created to monitor outcomes of IBD patients with confirmed COVID-19. The risk factors for severe COVID-19 among the 525 IBD patients published by Brenner et al. included older age, increasing number of comorbidities and systemic corticosteroids. Similarly to our results, they reported that anti TNF agents were not associated with severe COVID-19 and patients on TNF antagonists were younger and more likely to have CD [31]. Notably, our study only included eight patients with severe course of COVID-19, with no deaths. Two of them were treated with biologics and two with steroids. Therefore, our findings do not support the reported increased risk in corticosteroid use.

Smoking is most likely associated with negative progression and severe outcomes of COVID-19 [32,33]. Our cohort included a small percentage of smokers, resulting in no significant correlation to COVID-19 severity, although a trend was observed in the multivariate analysis ( $p=0.25, \mathrm{OR}=4, \mathrm{CI} 95 \%$ : 0.37-0.42).

A study limitation is the relatively small number of patients in the cohort. Therefore, there was no specific analysis regarding the dosage or the duration of each treatment prior to COVID-19 onset. However, IBD patients were enrolled from all over the country, which is a major strength of the study, since it makes the results more generalizable. The study was performed in the first few months of the COVID-19 pandemic, including low number of patients treated with corticosteroids that also emphasizes the native perspective of the disease without SARS-CoV-2 variants and still without the effect of vaccination.

In summary, our study supports recent reports showing that there is no evidence for aggravated outcomes in patients with IBD in the context of COVID-19. Therefore, patients should probably continue their scheduled IBD-specific medications. Moreover, our findings may suggest a favorable outcome for patients receiving biologic treatment. However, in severe cases in which experimental medications are given (e.g., remdesivir), drug-drug interactions should be considered.

Author Contributions: Data curation, L.L., B.K., I.A.-B., B.O., O.B.-B., T.N., U.K., Y.H., H.B.E., R.E., A.L.-Z., A.H., E.Z., N.M., M.W., E.I., I.G., J.E.O., H.Y., B.U., B.A., D.B.H., B.M., O.S., Z.S., I.D., S.H.O., S.B.-H., Y.S., Y.M., E.B., E.G., S.D., Y.R., N.A.C., E.M., M.Z., S.O., N.A.F., E.S., Y.C., T.E., H.R.-M., A.S., A.Z. and A.B.-G.S.; writing-original draft, L.L. and A.B.Y.; writing-review and editing, I.D., S.H.O. and A.B.-G.S. All authors have read and agreed to the published version of the manuscript.

Funding: This research received no external funding.

Institutional Review Board Statement: The study was conducted according to the guidelines of the declaration of Helsinki and approved by the Institutional Review Board of Shaare Zedek Medical Center (protocol code: 0020-19).

Informed Consent Statement: For this type of study informed consent is not required.

Data Availability Statement: The data presented in this study are available on request from the corresponding author. The data are not publicly available fur to ethical restrictions.

Conflicts of Interest: U.K. reports research support from Takeda, Janssen and Medtronic; speaker/ advisory fees from AbbVie, Takeda, Janssen, M.S.D., Falk Pharma and Medtronic. R.E. reports consulting/speaker fees from AbbVie, Takeda, Janssen and Medtronic. E.Z. reports research support and consulting fees from Janssen, AbbVie, Takeda, Neopharm and Pfizer. N.M. reports research support from Takeda and Janssen; consulting fees from Janssen, Pfizer, Neopharm and BiomX; 
speaker fees from AbbVie, Pfizer and Takeda. M.W. reports consulting fees from AbbVie, Janssen, Takeda, Pfizer, Medtronic and Neopharm; speaker fees from AbbVie, Janssen and Takeda. H.Y. reports consulting/speaker fees from AbbVie, Janssen, Takeda, Pfizer, Falk Pharma, Neopharm and Given Imaging. I.D. reports research support from Pfizer and Altman Research; consulting/advisory fees from Takeda, Janssen, AbbVie, Celltrion, Arena Pharmaceuticals, Neopharm, Roche/Genentech, Pfizer, Medtronic, Gilead, Ferring, Rafa Laboratories, Given Imaging, M.S.D., Protalix and Sublimity Therapeutics; speaker/teaching fees from Takeda, Janssen, AbbVie, Ferring, Falk Pharma, Given Imaging, Roche/Genentech, Pfizer, Celltrion and M.S.D. S.B.-H. reports research support from Takeda, AbbVie, Celltrion, Pfizer and Janssen; consulting fees from Janssen, Takeda, AbbVie, Celltrion, SBH, GSK, Ferring and Pfizer. E.G. reports consulting fees from Janssen, Takeda, AbbVie and Digma Medical. YC reports grant support from AbbVie, Takeda, Janssen, Medtronic and Protalix; speaker fees from AbbVie, Takeda, Janssen and Ferring. A.B.-G.S. reports consulting/advisory fees from Takeda, Janssen, Neopharm, Pfizer and AbbVie; speaker/teaching fees from Takeda, Janssen, AbbVie, Neopharm and Rafa Laboratories; research support from Takeda and Janssen. The remaining authors have no conflicting interests to declare.

\section{References}

1. Kirchgesner, J.; Lemaitre, M.; Carrat, F.; Zureik, M.; Carbonnel, F.; Dray-Spira, R. Risk of Serious and Opportunistic Infections Associated with Treatment of Inflammatory Bowel Diseases. Gastroenterology 2018, 155, 337-346.e10. [CrossRef]

2. Beaugerie, L.; Kirchgesner, J. Balancing Benefit vs. Risk of Immunosuppressive Therapy for Individual Patients with Inflammatory Bowel Diseases. Clin. Gastroenterol. Hepatol. 2019, 17, 370-379. [CrossRef]

3. Hu, B.; Guo, H.; Zhou, P.; Shi, Z.L. Characteristics of SARS-CoV-2 and COVID-19. Nat. Rev. Microbiol. 2021, 19, 141-154. [CrossRef]

4. Harmer, D.; Gilbert, M.; Borman, R.; Clark, K.L. Quantitative mRNA expression profiling of ACE 2, a novel homologue of angiotensin converting enzyme. FEBS Lett. 2002, 532, 107-110. [CrossRef]

5. Allocca, M.; Fiorino, G.; Zallot, C.; Furfaro, F.; Gilardi, D.; Radice, S.; Danese, S.; Peyrin-Biroulet, L. Incidence and Patterns of COVID-19 Among Inflammatory Bowel Disease Patients From the Nancy and Milan Cohorts. Clin. Gastroenterol. Hepatol. 2020, 18, 2134-2135. [CrossRef]

6. Guan, W.-J.; Ni, Z.-Y.; Hu, Y.; Liang, W.-H.; Ou, C.-Q.; He, J.-X.; Liu, L.; Shan, H.; Lei, C.-L.; Hui, D.S.C.; et al. Clinical Characteristics of Coronavirus Disease 2019 in China. N. Engl. J. Med. 2020, 382, 1708-1720. [CrossRef]

7. Ejaz, H.; Alsrhani, A.; Zafar, A.; Javed, H.; Junaid, K.; Abdalla, A.E.; Abosalif, K.O.; Ahmed, Z.; Younas, S. COVID-19 and comorbidities: Deleterious impact on infected patients. J. Infect. Public Health 2020, 13, 1833-1839. [CrossRef]

8. Burke, K.E.; Kochar, B.; Allegretti, J.R.; Winter, R.W.; Lochhead, P.; Khalili, H.; Colizzo, F.P.; Hamilton, M.J.; Chan, W.W.; Ananthakrishnan, A.N. Immunosuppressive Therapy and Risk of COVID-19 Infection in Patients with Inflammatory Bowel Diseases. Inflamm. Bowel Dis. 2021, 27, 155-161. [CrossRef]

9. Ludvigsson, J.F.; Axelrad, J.; Halfvarson, J.; Khalili, H.; Larsson, E.; Lochhead, P.; Roelstraete, B.; Simon, T.G.; Söderling, J.; Olén, O. Inflammatory bowel disease and risk of severe COVID-19: A nationwide population-based cohort study in Sweden. United Eur. Gastroenterol. J. 2021, 9, 177-192. [CrossRef]

10. Rubin, D.T.; Abreu, M.T.; Rai, V.; Siegel, C.A.; Ahuja, V.; Allez, M.; Ananthakrishnan, A.N.; Bernstein, C.N.; Braun, J.G.; Chowers, Y.; et al. Management of Patients with Crohn's Disease and Ulcerative Colitis During the Coronavirus Disease-2019 Pandemic: Results of an International Meeting. Gastroenterology 2020, 159, 6-13.e6. [CrossRef]

11. Kennedy, N.A.; Jones, G.-R.; Lamb, C.A.; Appleby, R.; Arnott, I.; Beattie, R.M.; Bloom, S.; Brooks, A.J.; Cooney, R.; Dart, R.J.; et al. British Society of Gastroenterology guidance for management of inflammatory bowel disease during the COVID-19 pandemic. Gut 2020, 69, 984-990. [CrossRef] [PubMed]

12. Satsangi, J.; Silverberg, M.S.; Vermeire, S.; Colombel, J.F. The Montreal classification of inflammatory bowel disease: Controversies, consensus, and implications. Gut 2006, 55, 749-753. [CrossRef] [PubMed]

13. COVID-19 Treatment Guidelines Panel. Coronavirus Disease 2019 COVID-19 Treatment Guidelines; The National Institutes of Health: Bethesda, MD, USA, 2019.

14. Aziz, M.; Fatima, R.; Haghbin, H.; Lee-Smith, W.; Nawras, A. The Incidence and Outcomes of COVID-19 in IBD Patients: A Rapid Review and Meta-analysis. Inflamm. Bowel Dis. 2020, 26, e132-e133. [CrossRef] [PubMed]

15. Monteleone, G.; Ardizzone, S. Are Patients with Inflammatory Bowel Disease at Increased Risk for Covid-19 Infection? J. Crohn's Colitis 2020, 14, 1334-1336. [CrossRef]

16. Singh, S.; Khan, A.; Chowdhry, M.; Bilal, M.; Kochhar, G.S.; Clarke, K. Risk of Severe Coronavirus Disease 2019 in Patients with Inflammatory Bowel Disease in the United States: A Multicenter Research Network Study. Gastroenterology 2020, 159, 1575-1578.e4. [CrossRef]

17. Singh, A.K.; Jena, A.; Kumar-M, P.; Sharma, V.; Sebastian, S. Risk and outcomes of coronavirus disease in patients with inflammatory bowel disease: A systematic review and meta-analysis. UEG J. 2020, 9, 159-176. [CrossRef]

18. An, P.; Ji, M.; Ren, H.; Su, J.; Ding, N.S.; Kang, J.; Yin, A.; Zhou, Q.; Shen, L.; Zhao, L.; et al. Prevention of COVID-19 in patients with inflammatory bowel disease in Wuhan, China. Lancet Gastroenterol. Hepatol. 2020, 5, 525-527. [CrossRef] 
19. Hanauer, S.B.; Feagan, B.G.; Lichtenstein, G.R.; Mayer, L.F.; Schreiber, S.; Colombel, J.F.; Rachmilewitz, D.; Wolf, D.C.; Olson, A.; Bao, W.; et al. Maintenance infliximab for Crohn's disease: The ACCENT I randomised trial. Lancet 2002, 359, 1541-1549. [CrossRef]

20. Colombel, J.F.; Sandborn, W.J.; Reinisch, W.; Mantzaris, G.J.; Kornbluth, A.; Rachmilewitz, D.; Lichtiger, S.; D’Haens, G.; Diamond, R.H.; Broussard, D.L.; et al. Diamond Infliximab, azathioprine, or combination therapy for Crohn's disease. N. Engl. J. Med. 2010, 362, 1383-1395. [CrossRef]

21. Din, S.; Cochrane, C.J.; Noble, C.L.; Satsangi, J.; Arnott, I.D. Combination therapy of infliximab and azathioprine reduces disease progression in Crohn's disease. Inflamm. Bowel Dis. 2008, 14, 143-145. [CrossRef]

22. Gianfrancesco, M.; Hyrich, K.L.; Al-Adely, S.; Carmona, L.; Danila, M.I.; Gossec, L.; Izadi, Z.; Jacobsohn, L.; Katz, P.; LawsonTovey, S.; et al. Characteristics associated with hospitalisation for COVID-19 in people with rheumatic disease: Data from the COVID-19 Global Rheumatology Alliance physician-reported registry. Ann. Rheum. Dis. 2020, 79, 859-866. [CrossRef] [PubMed]

23. Garg, M.; Royce, S.G.; Tikellis, C.; Shallue, C.; Batu, D.; Velkoska, E.; Burrell, L.M.; Patel, S.K.; Beswick, L.; Jackson, A.; et al Imbalance of the renin-angiotensin system may contribute to inflammation and fibrosis in IBD: A novel therapeutic target? Gut 2020, 69, 841-851. [CrossRef] [PubMed]

24. Garg, M.; Burrell, L.M.; Velkoska, E.; Griggs, K.; Angus, P.W.; Gibson, P.R.; Lubel, J.S. Upregulation of circulating components of the alternative renin-angiotensin system in inflammatory bowel disease: A pilot study. J. Renin-Angiotensin-Aldosterone Syst. 2014, 16, 559-569. [CrossRef] [PubMed]

25. Batlle, D.; Wysocki, J.; Satchell, K. Soluble angiotensin-converting enzyme 2: A potential approach for coronavirus infection therapy? Clin. Sci. 2020, 134, 543-545. [CrossRef]

26. Mehta, A.K.; Gracias, D.; Croft, M. TNF activity and T cells. Cytokine 2018, 101, 14-18. [CrossRef]

27. Burgueño, J.F.; Abreu, M.T. Reply to the Letter to the Editor: The Incidence and Outcomes of COVID-19 in Patients with IBD: A Rapid Review and Meta-Analysis. Inflamm. Bowel Dis. 2020, 26, e127. [CrossRef]

28. Mahase, E. Covid-19: Anti-TNF drug adalimumab to be trialled for patients in the community. BMJ 2020, 371, m3847. [CrossRef]

29. Sandborn, W.J.; Ghosh, S.; Panes, J.; Vranic, I.; Su, C.; Rousell, S.; Niezychowski, W. Tofacitinib, an oral Janus kinase inhibitor, in active ulcerative colitis. N. Engl. J. Med. 2012, 367, 616-624. [CrossRef]

30. Weisshof, R.; Golan, M.A.; Sossenheimer, P.H.; El Jurdi, K.; Ollech, J.E.; Pekow, J.; Cohen, R.D.; Sakuraba, A.; Dalal, S.; Rubin, D.T. Real-World Experience with Tofacitinib in IBD at a Tertiary Center. Am. J. Dig. Dis. 2019, 64, 1945-1951. [CrossRef]

31. Brenner, E.J.; Ungaro, R.C.; Gearry, R.B.; Kaplan, G.G.; Kissous-Hunt, M.; Lewis, J.D.; Ng, S.C.; Rahier, J.-F.; Reinisch, W.; Ruemmele, F.M.; et al. Corticosteroids, But Not TNF Antagonists, Are Associated with Adverse COVID-19 Outcomes in Patients with Inflammatory Bowel Diseases: Results From an International Registry. Gastroenterology 2020, 159, 481-491.e3. [CrossRef]

32. Vardavas, C.I.; Nikitara, K. COVID-19 and smoking: A systematic review of the evidence. Tob. Induc. Dis. 2020, 18, 20. [CrossRef] [PubMed]

33. Jimenez-Ruiz, C.A.; Lopez-Padilla, D.; Alonso-Arroyo, A.; Aleixandre-Benavent, R.; Solano-Reina, S.; de Granda-Orive, J.I. COVID-19 and Smoking: A Systematic Review and Meta-Analysis of the Evidence. Arch. Bronconeumol. 2020, 57, 21-34. [PubMed] 